\section{Assessment of spatial egocentrism through expectancy violation}

\author{
CAROLYN U. SHANTZ, The \\ Merrill-Palmer Institute, Detroit, Mich. \\ 48202, and JOHN S. WATSON, University \\ of California, Berkeley, Calif. 94720
}

Forty-eight preschool Ss were presented a situation in which, under a "trick" condition, their spatial movement did not result in appropriate transformations of perspective of a visual display. Comparison of visual exploration, facial, and verbal responses on trick and control trials showed significant facial and verbal reaction to the trick condition. The results are viewed as indicating an important early period in the waning of spatial egocentrism.

Egocentrism refers to a person's lack of awareness that other people may not hold his view of, or attitudes about, a given situation or event. The waning of egocentrism in childhood has been viewed by Piaget (Piaget \& Inhelder, 1956; Piaget, 1967) and others (Feffer, 1959; Feffer \& Suchotliff, 1966; Cowan, 1966) as a central cognitive and social development. In Piaget's words, "The important point is that ... the child of seven years begins to be liberated from his social and intellectual egocentricity and becomes capable of new coordinations which will be of the utmost importance in the development of intelligence and affectivity [1967, p. 41]."

Piaget's major study of egocentrism has been of the spatial egocentrism of children 4 to 9 years of age (Piaget \& Inhelder, 1956). In his experiments, Piaget presented a child with a landscape display of three mountains and asked the child to imagine what a doll "saw" from various locations around the landscape. Piaget reports that, prior to 7 years of age, children generally assume that the doll sees what they see, regardless of the doll's position. It is only at about $7-8$ years of age that they begin to be aware that the doll's viewpoint differs from their own and of how it differs.

While Piaget's data clearly indicate that the younger children were unable to perform the landscape task, his experiments do not provide much information as to why they failed. Should we assume that the egocentric behavior displayed by Piaget's average 5-year-old is based on the child's belief that a visual object has only the one perspective he is momentarily viewing, or is it that even children younger than 7 years of age have a notion that a perspective of a visual object changes as they move, but that they are simply unable to apply this knowledge within the classic Piagetean spatial task?

The difference between these two possible views of the early period of egocentric spatial behavior is perhaps best contrasted by the different predictions one would make were one to show a visual display to a child and then, after screening it, move the child to another position but provide him the same perspective he saw originally. If the child is aware that changes in perspective accompany changes in physical position relative to an object, then he should be surprised to find the same perspective available to him upon reexposure from a new position of regard. This "expectancy violation" procedure was used in the present study.

The use of expectancy violation as a means of assessing a child's cognitive status has been successfully employed previously in the study of conservation behavior (Charlesworth, 1964). In the present study, the less egocentric $S$ was expected to display his advanced cognitive status by responding to the "trick" conditions of the experiment with facial and/or verbal expressions denoting surprise, amusement, or perplexity. In addition, the tendency to increase perceptual. contact with the discrepant stimulus was employed as a dependent variable due to previous successful use of this variable with older children (Smock \& Holt, 1962).

$$
\text { SUBJECTS }
$$

Two groups of $24 \mathrm{Ss}$ were drawn from the Merrill-Palmer Institute Nursery School. The younger group ranged in age from 3 years 0 months to 4 years 2 months, with a mean of 3 years 9 months. The older group ranged from 4 years 2 months to 5 years 2 months, with a mean of 4 years 7 months. Each group was composed of 12 boys and 12 girls.

\section{METHOD}

The Ss were given the opportunity to view the contents of a specially constructed box. The box was a 4-cft cube with a slot for viewing the contents on two opposite sides, termed the 0 -deg and 180-deg positions. The contents could be seen only when and for as many times as a $1 / 2$-sec-duration light inside the box was activated by Ss pressing a button under the viewing slot.

The contents of the box were either of two stimulus displays. One display was a small doll seated on a chair in front of a TV set; the other was a house, a car, and a tree, with a road and sidewalk drawn in ink. The procedure involved real conditions and trick conditions. In the former, the change in the perspective of objects was the natural consequence of S's physical movement to the opposite side of the box, i.e., perspective was different by $180 \mathrm{deg}$. The trick conditions were obtained by (1) rotating the stimulus display $180 \mathrm{deg}$ as $S$ moved $180 \mathrm{deg}$ so that the object arrangement was identical to what $S$ viewed at the 0 -deg position, and (2) rotating the display $90 \mathrm{deg}$ as $S$ moved $180 \mathrm{deg}$. The trick conditions were accomplished by a hidden pulley system. A masking sound was constantly provided to cover any slight pulley-movement noise, and the pulleys were operated on all real trials as well as trick trials to assure unbiased stimulus presentation.

All Ss were administered both conditions with four trials per condition. In both the real and the trick condition, the $\mathrm{S}$ viewed the display from the 0 -deg, then 180-deg, then 0-deg, and then 180-deg positions. In the real condition, the display remained stationary, but in the trick condition, the display was rotated $180 \mathrm{deg}$ between Trials 1 and 2 , rotated $180 \mathrm{deg}$ again between Trials 2 and 3 , and then rotated 90 deg between Trials 3 and 4 . Half the Ss were given the real condition before the trick condition, and half received the reverse order. The stimulus display was changed between the two conditions for each $S$ in order to minimize decreasing interest in the later trials. Half the Ss had the "indoor" display first, and half had the "outdoor" display first. Across Ss, the order of stimulus displays was counterbalanced with the order of experimental conditions.

The $S$ was placed at the 0 -deg viewing position, and the following introductory instructions were given: "Stand here. This is a peak-in-the-box. You can see a doll sitting in a chair looking at TV (or a house, car, and tree) when you look through this window. You may look as long as you wish. Push this button to make the light go on."

When $S$ appeared to have finished looking, E asked: "Would you like to look in this window some more, or would you like to look in that window?" On the fourth trial, when $S$ indicated he would like to change windows, E stated: "Oh, I just remembered. My friend is going to put some new things in the box for you to see. Let's go get a drink of water while my friend fixes the box for us, and then we'll peak in the box again and see what's in there." S was taken to a nearby room while the display was changed by another $\mathrm{E}$. Average time of this break was $1 \mathrm{~min}$ $10 \mathrm{sec}$. On the fourth trial of the second 
condition, when $S$ indicated he was through viewing, $\mathrm{E}$ informed him that the game was over and then asked which display he liked looking at most.

Three dependent variables were employed: (1) frequency of light presses per trial, (2) frequency of facial responses indicating surprise, amusement, or perplexity, and (3) verbalizations indicating awareness of inappropriate perspective, surprise, perplexity, amusement, or realization that the display had turned. The light presses were recorded by an event recorder, the facial responses were recorded by a second $E$ in an observation booth, who was unaware of which condition $S$ was being administered, and verbalizations were tape-recorded.

\section{RESULTS}

The frequency of light presses per trial were analyzed in a 2 by 2 by 3 analysis of variance focusing on age, experimental condition, and trials (the second, third, and fourth trials since the first trial was the same for all Ss in both conditions). The analysis revealed no significant main effects or interactions.

Analysis was made of the relative frequency of facial responses indicating amusement, surprise, or perplexity on the second through fourth trials of the two experimental conditions. Twenty-eight Ss showed a differential frequency of relevant facial responses under the trick and real conditions. Nineteen Ss made more such responses under the trick and nine made more under the real condition. A sign test of these frequencies is significant $(Z=1.70, p<.05)$.

The verbatim records of the $S$ s were analyzed for the occurrence of relevant verbalizations as described above. Two judges independently rated the occurrence of relevant verbalizations and their level of agreement was $96 \%$. The frequency of relevant verbalizations on the second through fourth trials of the two experimental conditions was analyzed. These data were very discriminating. Of the $48 \mathrm{Ss}, 22$ made such verbalizations under the trick condition only, one $S$ made such verbalizations under the real condition only, while $21 \mathrm{Ss}$ made no such verbalizations, and 4 Ss made relevant verbalizations under both conditions. Considering Ss who verbalized more under one than under the other of the two conditions, 23 of 24 Ss made more relevant verbalizations under the trick condition (sign test, $\mathrm{p}<.001$ ).

The variables of sex and age did not show main effects on any of the three dependent variables. The effect of the order of the two experimental conditions appeared only in the case of relevant verbalizations. It was found that when verbalizations occurred under the trick condition, they occurred significantly more often when the trick condition was administered after the real condition than in the reverse order $\left(\chi^{2}=4.11, p<.05\right)$. Finally, there were no main effects of the difference in stimulus displays, with the exception that upon inquiry the girls stated a preference for the indoor display, while the boys generally preferred the outdoor display $\left(\chi^{2}=4.42, p<.05\right)$.

\section{DISCUSSION}

The results of the present study provide some initial information concerning spatial expectancies of preschool children. About half of the sample of 3- to 5-year-olds clearly differentiated the trick and real conditions as judged by their verbalizations. Of the $48 \mathrm{Ss}, 14$ not only realized that something different from what they had expected had occurred but described the difference as having involved stimulus movement or turning. A significant, though less marked, experimental effect appeared with the facial response variable. A side point worth noting here is that in a study by Charlesworth \& Zahn (1966) of the apparent violation of the effect of rotation on the order of beads in a tube, the 6- to 7-year-old Ss showed "an almost complete absence of verbal or vocal responses" indicating surprise or perplexity. It thus appears that preschoolers may be more prone to verbalize when experiencing unexpected events than are older children.

The authors had two theoretical expectancies that were unfulfilled by the data of this study. On the one hand, we expected the light-press data to be sensitive to the experimental manipulations. Casual observation suggests that a possible reason it was not sensitive in this study is that, while some children seemed to take longer looks in the trick condition, others looked less long as an effect of being eager to change to another position of regard, as if they suspected that something was "amiss" and wished to check their suspicions. Thus, while the present data are divergent from the results obtained by Smock \& Holt (1962), it may be that increased visual contact with conceptually conflictual displays occurs only if the $S$ believes that his existing situation (trial) provides his only opportunity to resolve the conflict.

Our second unfulfilled expectancy was the lack of a main effect of age on the three dependent variables. Of course, this null finding may reflect either the fact that there are no relevant age differences within the age range tested here or that the method employed here was insufficient to uncover an existing difference. It seems clear, however, that the present method is considerably more sensitive to the existence of an early coordination of transformations in spatial position and transformations in visual perspective than is the Piagetean landscape task.

In Piaget's study, 4- and 5-year-olds were found to seldom understand the task requirements of inferring what a doll saw from various locations, and the earliest case cited of a child being aware that the doll "sees" something different was at 6 years 10 months. In contrast, the results of the present study indicate that many children of even 3 and 4 years of age have at least gross expectancies of the relation between their position in space relative to an object and the appearance of that object.

The complete waning of spatial egocentrism would seem to require that the child both construct a system that coordinates transformations in spatial movement and transformations in perspective and also learn to apply that system to anticipated or symbolically represented moves in space (e.g., as in "assuming" the position of a doll looking at a landscape). If so, an important period in the waning of spatial egocentrism appears to exist considerably earlier in childhood than previous research would imply.

\section{REFERENCES}

CHARLESWORTH, W. R. Instigation and maintenance of curiosity behavior as a function of surprise versus novel and familiar stimuli. Child Development, 1964, 35, 1169-1186.

CHARLESWORTH, W. R., \& ZAHN, C. Reaction time as a measure of comprehension of the effects produced by rotation on objects. Child Development, 1966, 37, 253-268.

COWAN, P. Cognitive egocentrism and social interaction in children. Paper read at American Psychological Association meeting, New York, September 1966.

FEFFER, M. H. The cognitive implications of role taking behavior. Journal of Personality, $1959,27,152-168$.

FEFFER, M. H., \& SUCHOTLIFF, L. Decentering implications of social interactions. Journal of Personality \& Social Psychology, $1966,4,415-422$.

PIAGET, J. Six psychological studies. New York: Random House, 1967.

PIAGET, J., \& INHELDER, B. The child's conception of space. London: Routledge \& Kegan Paul, 1956.

SMOCK, C. D., \& HOLT, B. G. Children's reactions to novelty: An experimental study of curiosity motivation. Child Development, $1962,33,631-642$.

\section{NOTE}

1. This research was supported in part by OEO Head Start Subcontract No. 1410 with Michigan State University Head Start Evaluation and Research Center. 